\title{
DETERMINAÇÕES SOCIAIS DA SAÚDE E OS DESAFIOS NA PROPAGAÇÃO E COMBATE AO COVID-19
}

\author{
Renata Lima Oliveira ${ }^{1}$ \\ Ana Carolina Miano ${ }^{2}$ \\ Leodinilde Pinto Caetano ${ }^{3}$ \\ Mercedes Queiroz Zuliani ${ }^{4}$ \\ Daniela Queiroz Zuliani ${ }^{5}$
}

\begin{abstract}
Resumo
No final de 2019 foi identificada em Wuhan na China uma doença infecciosa com alto índice de transmissão entre os humanos, que foi denominada COVID-19. Em pouco tempo, essa doença atingiu diversas regiões do mundo e se transformou em uma pandemia, com imensos impactos na vida das pessoas e no ambiente. Este artigo tem como objetivo explorar as relações existentes entre a saúde e ambiente, no momento atual de enfrentamento à COVID-19 no Brasil, com foco nas questões socioambientais envolvendo a poluição, o saneamento e a aglomeração e suas consequências/limites para a prevenção/atenção em saúde. Para o desenvolvimento da pesquisa, trabalhou-se a revisão, entre maio e junho de 2020. O artigo traz aspectos sobre a revolução industrial e sua relação com formas de vida; a questão do saneamento, da aglomeração como reflexo das desigualdades geográficas e seus impactos sobre o combate à COVID-19. Assim, urge a compreensão das várias medidas sanitárias, que dialoguem com as ações ambientais, sociais, políticas que precisam ser construídas, nas diversas dimensões, no sentido ao combate das desigualdades socioambientais.
\end{abstract}

Palavras-chave: COVID- 19; Aglomeração; Saneamento Básico; Poluição Ambiental.

\section{Introdução}

Diante da crise pandêmica em que vivemos e considerando a possibilidade de sua origem no mercado de animais da China (ONU, 2020), é fundamental retomar a compreensão sobre as determinações sociais do processo saúde-doença para o entendimento de como as

\footnotetext{
${ }^{1}$ Formada em Agronomia pela Universidade da Integração Internacional da Lusofonia Afro-brasileira (UNILAB), Mestranda na Universidade Estadual Paulista "Júlio de Mesquita Filho" (UNESP), Bolsista do Centro de Ciências e Tecnologia para a Soberania e Segurança Alimentar e Nutricional da UNESP (INTERSSAN), renata_limapacoti@hotmail.com. Orcid 0000-0002-9730-1656.

2 Graduanda em Nutrição na Universidade Estadual Paulista "Júlio de Mesquita Filho" (UNESP), ana.c.miano@unesp.br, Orcid 0000-00021266-3376

${ }^{3}$ Formada em Agronomia pela Universidade da Integração Internacional da Lusofonia Afro-brasileira (UNILAB), Mestranda na Universidade Estadual Paulista "Júlio de Mesquita Filho" (UNESP), Bolsista do Centro de Ciências e Tecnologia para a Soberania e Segurança Alimentar e Nutricional da UNESP (INTERSSAN), 1leopica@gmail.com, Orcid 0000-0002-9730-1656

${ }_{5}^{4}$ Mestranda na Universidade Federal do Espírito Santo.

${ }^{5}$ Professora Adjunta na Universidade da Integração Internacional da Lusofonia Afro-brasileira (UNILAB) danielaqzuliani@unilab.edu.br
} 
questões sócio-ambientais influem no processo de adoecimento das populações e nas ações intersetoriais necessárias neste momento.

As determinações sociais da saúde (DSS) são um conjunto de fatores sociais, econômicos, culturais, étnico/raciais, psicológicos e comportamentais que influenciam a ocorrência de problemas de saúde e os fatores de risco na população. Os estudos em DSS buscam entender os mecanismos de produção das iniquidades em saúde (BUSS; FILHO, 2007).

A origem de mais uma pandemia é expressão da ruptura metabólica na natureza, como nos ensina Foster (2017), com as contradições do sistema capitalista, que para sua reprodução na sociedade moderna, precisa avançar sobre os bens da natureza e ampliar a exploração do trabalho (LEFT VOICE, 2017). Isso se dá de maneira diversa nos vários países, de acordo com a divisão internacional do trabalho, que, pós revolução industrial, segue ampliando estas rupturas. Foster (2017) trouxe, em suas pesquisas:

O fato do capitalismo impor suas leis ao meio ambiente independentemente dos ciclos biogeoquímicos do planeta e de seu metabolismo, de modo que cria fendas ou rupturas nos ciclos biogeoquímicos da Terra, interrompendo as relações do ecossistema de maneiras que transcendem os meros efeitos de escala do crescimento econômico. É o problema da ruptura metabólica o nosso desafio mais profundo. A sustentabilidade é cada vez mais comprometida em níveis cada vez maiores - uma ameaça continuamente acelerada para a civilização e a própria vida (LEFT VOICE, 2017).

A pandemia encontra, além disso, vários países com suas perdas de direitos conquistados e aumento nas políticas de austeridade, que pioraram as condições de vida e saúde das populações. Elaborando sobre as determinações sociais em tempos de COVID-19, Souza (2020) aponta a fragilização dos sistemas de saúde bem como "os diferentes impactos que as doenças geram nas classes sociais, sobretudo nos grupos mais pauperizados" (SOUZA, 2020, p. 2476), indicando que a "pandemia pode impactar nas comunidades mais pauperizadas, especialmente nos países de capitalismo dependente, devido ao baixo acesso à água tratada, saneamento e estrutura e renda que permita adotar as medidas de prevenção" (SOUZA, 2020, p. 2476).

No Brasil, além destas crises, há ainda uma crise político-institucional, em que as divergências entre governo federal, estados e municípios e a não condução conjunta das políticas de saúde dificultam o combate à pandemia (MADEIRA et al., 2020). 
Reforçada na histórica lei $\mathrm{n}^{\mathrm{o}} 8.080$ de 19 de setembro de 1990 ,conquista do Movimento Sanitário Brasileiro, e amplamente discutido na 8 a Conferência Nacional de Saúde, "a saúde tem como fatores determinantes e condicionantes, entre outros, a alimentação, a moradia, o saneamento básico, o meio ambiente, o trabalho, a renda, a educação, o transporte, o lazer e o acesso aos bens e serviços essenciais; os níveis de saúde da população expressam a organização social e econômica do País" (BRASIL, 1990).

Ademais dessa relação entre saúde e suas determinações que o Movimento Sanitário Brasileiro traz, a saúde coletiva latino-americana, em sua práxis, elabora sobre as determinações sociais da saúde como uma das 3 categorias centrais para uma epidemiologia crítica (BREILH, 2013), tão necessária para este momento de enfrentamento ao novo coronavírus. Infere-se que as mudanças no modo de vida das populações, produzidas pelo modo de produção capitalista e que geram poluição ambiental, formas de aglomeração bem como deficiências nas condições de saneamento, tornam-se importantes como determinações do processo saúde-doença do novo coronavírus.

Destarte a importância de aprofundar os estudos sobre as questões essenciais na compreensão da propagação e combate ao COVID-19 a partir da realidade diversa das populações em seus territórios no país. Este artigo tem como objetivo explorar as relações existentes entre a saúde e ambiente no momento atual de enfrentamento ao COVID-19 no Brasil, com foco nas questões sócio-ambientais da poluição ambiental, do saneamento e da aglomeração e suas consequências/limites para a prevenção/atenção/vigilância em saúde, na compreensão da determinação social da saúde.

\section{Metodologia}

Para o desenvolvimento da pesquisa, trabalhou-se por meio de revisão, tendo como foco a busca por dados relacionados a COVID-19 e fatores sociais de risco para o agravamento da pandemia no Brasil. Os repositórios consultados consistiram em revistas cientificas de áreas variadas, como exemplo da saúde e ciências humanas.

O artigo foi desenvolvido entre maio e junho de 2020, período em que o Brasil já se encontrava na elevação da curva de contágio do vírus da Covid-19, avançando sobre as periferias, áreas rurais e cidades do interior. Pergunta-se, então: qual o efeito dessas condições sobre a propagação e o combate à COVID-19? 
Utilizamos as bibliotecas eletrônica Scielo e PubMed associando o descritor COVID-19 a saneamento básico e em seguida à aglomeração; e os descritores de revolução industrial com a poluição ambiental, além disso utilizamos informações dos portais oficiais dos governos e de organizações como a Organização das Nações Unidas (ONU) e a Organização Mundial da Saúde (OMS) e também algumas notícias de jornais que vieram a complementar a temática abordada. $\mathrm{O}$ artigo prima pela seleção de publicações em revistas científicas nos últimos 5 anos, mas também, optou-se pela utilização de artigos publicados em períodos anteriores, quando estes trazem luz a fatos que são importantes para a compressão da atual situação global em relação à COVID-19. Em nossa busca foram excluídos todos os testes clínicos e os demais artigos que não abordavam a relação proposta pelos descritores.

Os principais descritores utilizados na pesquisa, para a obtenção de dados referentes à temática, foram: COVID-19, saneamento básico, aglomeração, poluição ambiental, revolução industrial, políticas públicas, desigualdade social.

\section{Resultados e Discussão}

\section{Revolução industrial e suas contribuições para os agravos de saúde}

A revolução industrial iniciada no século XVIII moldou as sociedades industriais contemporâneas, cenário no qual a população está inserida, sendo portando um dos fatores sociais que determinam a saúde (ONU BRASIL, 2020). No momento em que os produtores artesanais passam a formar a classe de trabalhadores assalariados e novas fontes de energia são instauradas, como a vapor; a combustão, proveniente de fontes renováveis ou não (carvão, petróleo); entre outras, temos alterações nas relações sociais e nas bases técnicas das atividades, que envolvem a ciência, a tecnologia e a mercantilização (FRANCO; DRUCK, 1998; (NEDER, 1994).

Há uma relação histórica muito forte entre os riscos industriais, o meio ambiente e a saúde da população (FRANCO; DRUCK, 1998). Podemos citar o primeiro caso que levou às autoridades em saúde a tomarem medidas em relação à qualidade do ar: em 1952 a cidade de Londres ficou encoberta por uma densa névoa de fumaça proveniente das fábricas, sendo responsável por matar mais de 12 mil pessoas por envenenamento, esse fenômeno ficou conhecido como smog (LONDRES..., 2020; POTTI; ESTRELA, 2017). Tendo como premissa 
as complicações respiratórias decorrentes da COVID-19 podemos entender melhor a relevância deste assunto.

A relação entre o ambiente intra e extrafabril sempre foi muito estreita, e essa noção se evidência ainda mais nos países periféricos onde há um desprovimento generalizado de informação, bem como uma cultura de segurança ambiental e industrial mais vulnerável, ou seja, os danos causados pelas fábricas vão além da sua estrutura física e os efeitos não se limitam ao tempo do acidente. E os principais problemas ambientais em razão de poluentes químicos são frutos dos padrões de industrialização iniciados nesse período (FRANCO; DRUCK, 1998).

Segundo dados da Organização Mundial da Saúde (OMS), divulgados também pela Organização das Nações Unidas (ONU, 2019), doenças relacionadas à poluição do ar matam 7 milhões de pessoas por ano. Em 2016, 600 mil crianças perderam a vida em decorrência de infecções respiratórias agudas causadas por poluição do ar. Já em 2018 foi constatado que 93\% das crianças do mundo - menores de 15 anos - são expostas a graves riscos de saúde e desenvolvimento por respirarem um ar tão poluído. Esse setor da sociedade se torna mais vulnerável a esse fator por respirar mais rápido que os adultos, além de se manterem mais próximos ao solo onde há maior concentração desses poluentes (OPAS, 2018). Neste mesmo ano foi realizada a primeira Conferência Global sobre Poluição do Ar e Saúde, sendo organizada pela OMS em conjunto com a ONU, Meio Ambiente e outros parceiros (ONU, 2019).

Em estudo realizado por Muhammad, Long e Salman (2020), o bloqueio de atividades devido ao COVID-19 tem algum efeito positivo no ambiente natural. Estes pesquisadores analisaram dados recentes divulgados pela NASA (Administração Nacional de Aeronáutica e Espaço) e ESA (Agência Espacial Europeia) e indicam que a poluição em alguns dos epicentros do COVID-19, como Wuhan, Itália, Espanha e EUA, reduziu para 30\%. Essa redução da poluição que está acontecendo em diversos lugares do mundo tem um impacto positivo também na saúde das pessoas, entretanto, pode ser momentâneo, visto que a volta as atividades têm sido a grande, e para alguns governos, a maior preocupação.

É importante citar também que uma das rotas pouco mencionadas de transmissão do vírus se dá com a dispersão das gotículas, que contêm a carga viral, pelo ar, alcançando dezenas de metros a partir da sua origem. A Sociedade Italiana de Medicina Ambiental (SIMA) trouxe a hipótese de uma possível ligação entre os altos índices de infecção por COVID-19 na região 
norte da Itália às altas concentrações de material particulado, ou PM da sigla em inglês, um conjunto de partículas poluentes muito finas suspensas no ar. Mais tarde pesquisas realizadas na Escola de Saúde Pública de Harvard sugeriram forte correlação da taxa de mortalidade por COVID-19 ao aumento da concentração de PM (LIZCANO; ARROYAVE, 2020).

De acordo com o atual Secretário Geral das Nações Unidas, António Guterres, nós poderíamos estar enfrentando melhor o desafio da pandemia se tivéssemos cumprido um pouco mais dos Objetivos de Desenvolvimento Sustentável (ONU BRASIL, 2020). Enquanto isso, o Programa das Nações Unidas para o Meio Ambiente enxerga no atual momento uma grande oportunidade para mudanças na estrutura da sociedade, para nos reconstruirmos melhor (ONU BRASIL, 2020).

Se os padrões de consumo e produção forem mantidos não haverá sustentabilidade para esse sistema, e a reestruturação destes padrões depende da existência e da participação de membros da sociedade que se reconheçam com tal e que possuam visibilidade (FRANCO; DRUCK, 1998). As relações de co-desenvolvimento entre homem e natureza precisam ser redefinidas e a verdadeira escolha se dá entre as formas de desenvolvimento que são sensíveis ou não às questões ambientais (NEDER, 1994).

\section{Saneamento e pandemias - um reflexo das desigualdades geográficas e seus impactos sobre o combate a COVID -19}

As desigualdades decorrentes da estratificação social no Brasil ao longo da nossa construção vem sendo objeto de debate, principalmente nas ciências sociais, que buscam mostrar as origens e resultantes advindos das desigualdades. As disparidades existentes entre os diferentes estratos que refletem na formação de uma paisagem de contrates em todos os setores, sendo brutal, principalmente no acesso a medidas de promoção da saúde. Como apontam Lesser e Kitron (2016), sobre a incidência de doenças, e os locais, naturalmente mais favoráveis à sua propagação:

A qualidade das moradias, a existência ou não de rede de água e esgoto, a temperatura (por exemplo, o efeito ilha de calor), a exposição prévia ao vírus e outros fatores ajudam a determinar as taxas de transmissão e de infecção. Pressupostos culturais e políticos sobre classe, gênero e raça influenciam tanto as decisões orçamentárias quanto as políticas. 
(LESSER; KITRON, 2016, p. 171)

Nota-se, em todos os níveis do território, a formação de áreas que são em parte excluídas, em parte sub atendidas, pelos planos de desenvolvimento, ficando evidente em momentos de crise, como o atual, que precisamos pensar medidas integradas para se promover a saúde preventiva, evitando a expansão do COVID-19, as disparidades nos planos de desenvolvimento. Como exemplo, segundo o censo do IBGE em 2010 havia 189.790.211 moradores em domicílios particulares permanentes, desses 5.780.694 não tinham banheiro nem sanitário de uso exclusivo do domicílio (IBGE, 2011).

Para Antunes et al. (2013), ao pensarem a distribuição espacial de agravos da saúde respiratória que acarretam internações, trazem em sua discussão o espaço geográfico como uma categoria a ser considerada na organização das estratégias de saúde as necessidades da população, pontuando que: "uma vez que os serviços de saúde são organizados em base espacial, o espaço geográfico pode permitir melhor adequação das ações de saúde às necessidades diferenciadas, auxiliando na adoção de intervenções mais equitativas referentes à atenção à saúde" (ANTUNES et al., 2013, p. 1247). Ao estudarem o cruzamento de fatores, tais como: renda, educação, aglomeração e saneamento, chegaram a conclusão, em análises feitas em um período de dois anos, em áreas com fragilidade social na Bahia que, "observa-se que as taxas de hospitalização por doenças do aparelho respiratório e seus principais tipos foram mais elevados nos estratos de piores condições de vida" (ANTUNES et al., 2013, p. 1352) e que os agravos são elevados em comparação com outras regiões, em todas as faixas etárias observadas.

Para pensar essa relação saúde e fragilidade social, podemos refletir dois casos. Primeiro a situação no nordeste brasileiro, que há anos sofre com os resultantes de longos períodos de estiagem, que nos últimos anos tem se agravado, inclusive pela maneira do uso e exploração do bioma caatinga que ocupa uma área importante do território nordestino. Assim, a escassez de água tem relação direta com agravos de saúde, seja pela dificuldade em ter água abundante para as operações de higiene, seja pela escassez da produção de alimentos, que acarretam níveis de insegurança alimentar. Isso é constatado pela inconstância no fornecimento de água, levando a população a se valer de fontes que muitas vezes não oferecem segurança ou constância no fornecimento. Num segundo caso, podemos pensar, considerando a distribuição geográfica das desigualdades, as periferias das grandes metrópoles, que, em grande parte, também não tem acesso a um sistema de abastecimento hídrico e esgoto. 
Em ambos casos, as medidas de saúde pensadas para o COVID-19 são falhas, visto que, a maior parte das medidas pensadas para barrar o avanço do vírus são baseadas no isolamento e medidas sanitárias, as quais a população dessas áreas não tem acesso, como também, por estarem lutando para manter suas necessidades básicas, com oportunidades desiguais, sendo outras questões colocadas, em parte, em segundo plano na lista de prioridades.

Souza et al. (2020), coloca em relação a coleta e destino dos resíduos, que nesse momento que, ter o controle, o acompanhamento seria um passo importante para o conhecimento da dimensão da pandemia por meio da carga viral depositada nesses resíduos. "Desta forma, as ações de monitoramento dos sistemas de esgotamento sanitário seriam importantes no sentido de somar forças nos mecanismos de vigilância, principalmente em países em que os casos têm aumentado de forma rápida, como o Brasil" (SOUZA et al., 2020, p. 4). A falta de estratégias integradas, de políticas e programas, seria determinante para uma maior qualidade de vida. $\mathrm{O}$ que a COVID-19 nos mostra nesse momento é a ineficácia dessas políticas para a garantia da saúde.

Nesse passo, os resíduos produzidos nesses espaços acabam conferindo insalubridade ao ambiente, e sendo fator determinante para o desencadear de doenças, podendo destacar as que tem como vetor mosquitos (dengue, zika, Chikungunya), doenças gastrointestinais, doenças da pele (LESSER; KITRON, 2016). No caso da atual pandemia, o descarte de resíduos, que é fator de risco para os agravos acima citados, entra como fator de perigo, devido ao seu descarte em locais impróprios, em que podem contaminar diretamente a população por meio do contato direto, inalação, ou contaminação de alimentos e fontes de água existentes no meio.

Nesse passo, todos aprendemos a importância de lavar não só as mãos, mas tudo que possa ter contato com o vírus em algum momento, e que entra em nossas casas. Muitas campanhas, em especial por meio de mídias sociais, surgiram como iniciativas para divulgar e esclarecer a população para essas medidas básicas. Mesmo assim, sabemos que o acesso aos meios necessários, tanto de informação, quanto aos materiais necessários é extremamente desigual. E que, esse processo é mais campanhista do que educativo com participação.

Voltando o olhar para questões estruturais pré-existentes, vemos alguns avanços foram iniciados entre os anos de 1970 e 1980, visando à diminuição dos agravos decorrentes de condições sanitárias inadequadas, essas iniciativas mais a frente integraram o Plano Nacional de Saneamento (PLANASA). "Nestes últimos anos, as principais normas que regulam o setor 
de saneamento estão representadas pela Lei 11.445/2007, que estabelece as diretrizes nacionais para o saneamento básico, e pela Lei 9.433/1997, referente à Política Nacional de Recursos Hídricos ." Para Leoneti, Prado e Oliveira (2011), mesmo com o estabelecimento das leis, que em muito, acabam no discurso, para custear os recursos necessários a uma maior cobertura no fornecimento de água, coleta e tratamento de esgoto, seria necessário passar por uma maior integração das esferas de poder público e pela integração de público e privado, para superar os baixos investimentos feitos até o ano de 2000, e as fragilidades em regiões como norte e nordeste.

Em 2019, relatório da Comissão de Serviços de Infraestrutura (CI), destacou que mais de 35 milhões de brasileiros ainda não possuíam água tratada em seus domicílios ou água de forma constante, e 48 milhões não possuíam coleta e tratamento de esgoto (AGÊNCIA SENADO, 2019). Segundo os levantamentos sobre percentual atendido por coleta de esgoto por região, Sudeste Centro-Oeste e Sul apresentaram índices mais elevados no percentual de cobertura pelo serviço de esgoto, concentrando respectivamente 78,54\%, 53,88\% e 43,93\% da população atendida. Já Norte e Nordeste, tem 10,24\% e 26,87\% (AGÊNCIA SENADO, 2019).

Notadamente, Norte e Nordeste apresentam os índices mais baixos no fornecimento do serviço de saneamento básico à população, como também, junto com o Sudeste, despontam no cenário nacional nos números de infectados e mortos pelo COVID-19. Os dados disponibilizados em 15 junho de 2020 pelo governo federal (BRASIL, 2020) apontam que no Brasil há até esta data, há 888.271 casos confirmados de COVID-19 e 43.959 óbitos confirmados. O número de casos confirmados por regiões brasileiras são: Nordeste 315.057, Sudeste 311.715, Norte 178.783, Centro-Oeste 43.602 e Sul 39.114. O número de óbitos até 15 de junho de 2020 é: Sudeste20.062, Nordeste 14.232, Norte 7.978, Sul 893 e Cento- Oeste 794. Diante deste cenário, percebe-se que mesmo nas regiões que há o atendimento, deixam a desejar, visto reunirem os estados que concentram grandes cidades e as mais populosas do país. A incidência de doenças, as condições socioeconômicas são fatores determinantes, chave, para se pensar como estamos enfrentando a COVID-19 e como vamos enfrentar tantas outras doenças, fragilidades sociais e exclusões, que mostram a força da estratificação social existente.

"Fica evidente que a resposta às emergências só é possível na presença de sistemas de saúde bem estruturados, com capacidade de vigilância e de pesquisa, conduzidos por uma massa crítica de profissionais bem formados e capacitados para ação nestas três vertentes" 
(VENTURA et al., 2020, p. 2). Segundo, porque as maiores disfunções da resposta brasileira estão relacionadas ao déficit de sustentabilidade das iniciativas de saneamento e de controle do vetor. Seja para a COVID-19, seja para tantas outras doenças que a população brasileira vem enfrentando anualmente, de forma repetitiva, novos hábitos e medidas estruturais no nível nacional será a chave para garantir mais segurança à população, como também para sua valorização enquanto sujeitos detentores de deveres, mas também de direitos. Conforme a epidemiologia crítica, seriam necessárias neste momento ações de prevenção, promoção, vigilância e assistência à saúde, em diálogo e construção com movimentos e organizações, com participação popular.

\section{Aglomerações e a COVID-19 no Brasil}

As fragilidades sociais são escancaradas através da população subalternizada no enfrentamento ao vírus, de Norte ao Sul através dos menos favorecidos que na maioria são pretos-pobres-periféricos, onde se sustentar significa quebrar as medidas de prevenção adotadas pelo governo porque para processos de redução de infecção em todos os lugares do mundo, se dá pelo isolamento e quarentena da sociedade, higienização e medidas para pormenorizar as contaminações (MACEDO; ORNELLAS; BOMFIM, 2020).

O Instituto Brasileiro de Geografia e Estatística (IBGE), em nota técnica emitida em 2020 aponta em versão preliminar que incorpora atualizações até dezembro de 2019 e é formada por 13151 Aglomerados Subnormais. Esses aglomerados estão localizados em 734 Municípios, em todos os Estados e no Distrito Federal, e totalizam 5127747 domicílios (IBGE, 2020). Nestes aglomerados concentram-se muitos moradores, normalmente em situações bastante precárias de saneamento básico e atenção à saúde.

No Brasil, o Ministério da Saúde implementou medidas para o enfrentamento da Covid19: Vigilância, Suporte laboratorial, Medidas de controle de infecção, Assistência, Assistência farmacêutica, Vigilância Sanitária - Medidas de saúde em pontos de entrada, Comunicação de risco e Gestão (BRASIL, 2020). Tudo, dado as incertezas devido ao insuficiente conhecimento científico sobre o novo coronavírus, a sua alta velocidade de disseminação e capacidade de provocar mortes em populações vulneráveis (WERNECK; CARVALHO, 2020). Para o enfrentamento da crise, os profissionais da saúde e autoridades têm destacado, como medida 
preventiva à propagação da Covid-19, causada pelo novo coronavírus, a relevância de que os brasileiros evitem aglomerações e o contato próximo com outras pessoas (SÃO PAULO, 2020).

A recomendação ocorre, segundo o Ministério da Saúde (BRASIL, 2020), porque a transmissão pelo vírus costuma ocorrer pelo ar ou por contato pessoal com secreções contaminadas, como: espirro; tosse; gotículas de saliva; contato físico com uma pessoa infectada; toque em objetos ou superfícies contaminadas (seguido de contato com boca, nariz ou olhos). Neste âmbito, para evitar transmissão através de secreções, as autoridades recomendam reduzir as chances de transmissão pelo contato com secreções, e a orientação é não permanecer perto de um grande número de pessoas.

A medida vale para cidadãos de qualquer faixa etária e de qualquer grupo social o que a torna genérica e com necessidades de enfrentamento diferentes a considerar; para exemplificar, traz-se o estado do Rio de Janeiro que explicita que a vulnerabilidade populacional frente ao Corona Vírus está intrinsecamente ligada as classes sociais que é evidenciada através da distribuição espacial (SANTOS et al., 2020).

\section{Conclusão}

Deste modo, urge a compreensão das várias medidas sanitárias, que dialoguem com as ações ambientais, sociais, políticas que precisam ser construídas, nas diversas dimensões, no sentido ao combate das desigualdades sócio-ambientais. Se considerarmos que as causas de agravamento do coronavírus e as dificuldades em combatê-lo são devido às condições estruturais, é fundamental que se construam saídas que integrem as diversas dimensões das determinações sociais, conforme destacam os autores da epidemiologia crítica, como Breilh (2013) que considera fundamental a relação direta com as lutas dos povos e organizações para superação do capitalismo, regime centrado na acumulação de riqueza e cuja incompatibilidade do sistema social imperante com o modo de civilização que o reproduz. Tão importante quanto isso é a construção de modos de viver saudáveis, impedindo rupturas metabólicas que podem tornar a vida impossível.

Além disso, compreender que a realidade em que vive e trabalha a maior parte das/dos trabalhadoras/es, em aglomerações, com poluição ambiental e sem saneamento adequado é que dificultam o enfrentamento ao novo coronavírus bem como a outras doenças. Diante disso, é preciso seguir com análise abrangente sobre as determinações sociais que envolvem o novo 
coronavírus, apreender as dimensões estruturantes da sociedade que trazem grandes desafios ao enfrentamento da doença e impulsiona a necessidade de novos estudos e interrelações no campo saúde-ambiente.

\section{Referências}

AGÊNCIA SENADO. Brasil tem $\mathbf{4 8} \%$ da população sem coleta de esgoto, diz Instituto Trata Brasil. Brasília, 2019.

ANTUNES, F. P. et al. Desigualdades sociais na distribuição espacial das hospitalizações por doenças respiratórias. Cad. Saude Publica, Rio de Janeiro, v. 7, n. 29, p. 1346-1356, 2013.

BRASIL. Decreto n ${ }^{\circ} 8.080$, de 19 de setembro de 1990. Dispõe sobre as condições para a promoção, proteção e recuperação da saúde, a organização e o funcionamento dos serviços correspondentes e dá outras providências, Diário Oficial da União: seção 1, Brasília, DF, p. 18055,20 set. 1990 .

BRASIL. Ministério da Saúde. Saúde anuncia orientações para evitar a disseminação do coronavírus. Brasília: Ministério da Saúde, 2020. Disponível em: https://www.saude.gov.br/noticias/agencia-saude/46540-saude-anuncia-orientacoes-paraevitar-a-disseminacao-do-coronavirus. Acesso em: 1 jun. 2020.

BREILH, J. La determinación social de lasalud como herramienta de transformaciónhacia una nuevasalud pública (salud colectiva). Rev. Fac. Nac. Salud Publica, Medellín, v. 31, p. 1327, 2013. Suplemento 1. Disponível em:

http://www.scielo.org.co/scielo.php?script=sci_arttext\&pid=S0120-

386X2013000400002\&lng=en\&nrm=iso. Acesso em: 12 jun. 2020.

BUSS, P. M.; PELLEGRINI FILHO, A. A saúde e seus determinantes sociais. Physis, Rio de Janeiro, v. 17, n. 1, p. 77-93, 2007.

FRANCO, T.; DRUCK, G. Padrões de industrialização, riscos e meio ambiente. Cienc.

Saúde Colet., Rio de Janeiro, v. 3, n. 2, p. 61-72, 1998.

FOSTER, J. B. "A ruptura metabólica de Marx foi a primeira análise a delinear uma visão global da crise ecológica sistêmica". [Tradução de Pamela Penha]. Disponível em $<$ https://gz.diarioliberdade.org/mundo/item/180441-john-bellamy-foster-a-rupturametabolica-de-marx-foi-a-primeira-analise-a-delinear-uma-visao-global-da-crise-ecologicasistemica.html>. Acesso em 04 de jun. de 2020.

INSTITUTO BRASILEIRO DE GEOGRAFIA E ESTATÍSTICA. Censo demográfico 2010: características da população e dos domicílios - resultados do universo. Rio de Janeiro: IBGE; 2011.

INSTITUTO BRASILEIRO DE GEOGRAFIA E ESTATÍSTICA - IBGE. Nota técnica 01/2020: Informações socioeconômicas e demográficas: subsídios ao enfrentamento à COVID-19. Rio de Janeiro. 2020. 
LEFT VOICE. John Bellamy Foster: a ruptura metabólica de Marx foi a primeira análise a delinear uma visão global da crise ecológica sistêmica. Tradução: Pamela Penha. Diário Liberdade, Galiza, 9 ago. 2017. Disponível em:

https://gz.diarioliberdade.org/mundo/item/180441-john-bellamy-foster-a-ruptura-metabolicade-marx-foi-a-primeira-analise-a-delinear-uma-visao-global-da-crise-ecologicasistemica.html. Acesso em: 4 jun. 2020.

LEONETI, A. B.; PRADO, E. L.; OLIVEIRA, S. V. W. B. Saneamento básico no Brasil: considerações sobre investimentos e sustentabilidade para o século XXI. Rev. Admin. Publica, Rio de Janeiro, v. 45, n. 2, p. 331-348, 2011. DOI http://dx.doi.org/10.1590/s003476122011000200003 .

LESSER, J.; KITRON, U. A geografia social do zika no Brasil. Estudos Avançados. Estud. Av., São Paulo, v. 30, n. 88, p. 167-175, 2016. DOI http://dx.doi.org/10.1590/s010340142016.30880012 .

LIZCANO, F.; ARROYAVE, F. El ambiente, lós desplazamientos y elriesgo cardiovascular enla pandemia de COVID-19. Rev. Colomb. Cardiol., Bogotá, v. 27, n. 3, p. 160-165, 2020.

LONDRES: névoa assassina matou 12 mil pessoas. El País, Madrid, 2020. History Notícias. Disponível em: https://br.historyplay.tv/noticias/londres-nevoa-assassina-matou-12-milpessoas. Acesso em: 4 jun. 2020.

MACEDO, Y. M.; ORNELLAS, J. L.; BOMFIM, H. F. COVID - 19 no Brasil: o que se espera para população subalternizada? Rev. Encatar Educ. Cult. Soc., Bom Jesus da Lapa, v. 2, p. 1-10, 2020.

MADEIRA, L. et al. Os estudos de políticas públicas em tempos de pandemia. Dados Rev. Cienc. Sociais, Rio de Janeiro, 2020. Disponível em: http://dados.iesp.uerj.br/os-estudos-depoliticas-publicas-em-tempos-de-pandemia/. Acesso em: 11 jun. 2020.

MUHAMMAD, S.; LONG, X.; SALMAN, M. COVID-19 pandemic and environmental pollution: a blessing in disguise? Sci. Total Environ., Amsterdam, v. 728, p. 138820, 2020. DOI https://doi.org/10.1016/j.scitotenv.2020.138820.

NEDER, Ricardo Toledo. Estratégias de transição para o século XXI: desenvolvimento e meio ambiente. Revista de Administração de Empresas, [S.L.], v. 34, n. 2, p. 89-91, abr. 1994. FapUNIFESP (SciELO). http://dx.doi.org/10.1590/s0034-75901994000200011

ORGANIZAÇÃO DAS NAÇÕES UNIDAS BRASIL. O Dia da Terra é mais importante do que nunca. Brasília: ONU Brasil, 2020. Disponível em: https://nacoesunidas.org/o-dia-daterra-e-mais-importante-do-que-nunca/. Acesso em: 4 jun. 2020.

ORGANIZAÇÃO DAS NAÇÕES UNIDAS. Conferência global sobre poluição do ar e saúde. Rio de Janeiro: Saúde Amanhã; Fiocruz, 2019. Disponível em: https://saudeamanha.fiocruz.br/conferencia-global-sobre-poluicao-do-ar-esaude/\#.XtmCAW5FzIV. Acesso em: 4 jun. 2020.

ORGANIZAÇÃO PAN AMERICANA DE SAÚDE. Mais de $\mathbf{9 0 \%}$ das crianças do mundo respiram ar tóxico todos os dias. Brasília: OPAS Brasil, 2018. Disponível em: https://www.paho.org/bra/index.php?option=com_content\&view=ar 
ticle\&id=5793:mais-de-90-das-criancas-do-mundo-respiram-ar-toxico-todos-osdias\&Itemid=839. Acesso em: 4 jun. 2020.

POTTI, C. M.; ESTRELA, C. E. Histórico ambiental: desastres ambientais e o despertar de um novo pensamento. Estud. Av., São Paulo, v. 31, n. 89, p. 271-283, 2017.

SANTOS, J. P. C. et al. Vulnerabilidade a formas graves de COVID-19: uma análise intramunicipal na cidade do Rio de Janeiro, Brasil. Cad. Saude Publica, Rio de Janeiro, v. 36, n. 5, p. e00075720, 2020. Disponível em:

http://www.scielo.br/scielo.php?script=sci_arttext\&pid=S0102-

311X2020000506001\&lng=en\&nrm=iso. Acesso em: 11 jun. 2020.

SÃO PAULO (Estado). Coronavírus: Entenda a importância de evitar aglomerações: transmissão da covid-19 costuma ocorrer pelo ar ou por contato pessoal com secreções contaminadas; recomendação vale para todas as idades 2020. Disponível em:

https://www.saopaulo.sp.gov.br/ultimas-noticias/coronavirus-entenda-a-importancia-deevitar-aglomeracoes/. Acesso em: 19 mar. 20.

SOUZA, D. O. A pandemia de COVID-19 para além das Ciências da Saúde: reflexões sobre sua determinação social. Cienc. Saude Colet., Rio de Janeiro, v. 25, n. 6, 2020. Disponível em: http:/www.cienciaesaudecoletiva.com.br/artigos/a-pandemia-de-covid19-para-alem-dasciencias-da-saude-reflexoes-sobre-sua-determinacao-social/17562? id=17562. Acesso em: 11 jun. 2020.

SOUZA, L. P. S. et al. Presença do novo coronavírus (SARS-CoV-2) nos esgotos sanitários: apontamentos para ações complementares de vigilância à saúde em tempos de pandemia.

Vigil. Sanit. Debate, Rio de Janeiro, v. 8, n. 3, p. 132-138, 2020. DOI

https://doi.org/10.22239/2317-269x.01624.

VENTURA, D. F. L. et al. Desafios da pandemia de COVID-19: por uma agenda brasileira de pesquisa em saúde global e sustentabilidade. Cad. Saúde Pública, Rio de Janeiro, v. 36, n. 4, p. e000440620, 2020. Disponível em:

http://cadernos.ensp.fiocruz.br/csp/artigo/1023/desafios-da-pandemia-de-covid-19-por-umaagenda-brasileira-de-pesquisa-em-saude-global-e-sustentabilidade. Acesso em: 07 jun. 2020.

WERNECK, G. L.; CARVALHO, M. S. A pandemia de COVID-19 no Brasil: crônica de uma crise sanitária anunciada. Cad. Saúde Pública, Rio de Janeiro, v. 36, n. 5, p. e00068820, 2020. DOI https://doi.org/10.1590/0102-311X00068820.

\title{
SOCIAL DETERMINATIONS OF HEALTH AND THE CHALLENGES IN BLOCKING PROPAGATION AND COMBATING COVID-19
}

\begin{abstract}
In late 2019, an infectious disease with a high rate of human-to-human transmission was identified in Wuhan, China, which was called Covid-19. In a short time, this disease affected several regions of the world and became a pandemic, with huge impacts on people's lives and the environment. This article aims to investigate the existing relationships between health and
\end{abstract}


the environment, at the moment of confronting Covid-19 in Brazil, focusing on the socioenvironmental issues of sanitation and agglomeration and its consequences/limits for prevention/care in Public Health. For the development of the research, a systematic review was carried out between May and June 2020. The article brings aspects about the industrial revolution and its relationship with life forms; the issue of sanitation, agglomeration as a reflection of geographical inequalities and their impact on combating Covid-19. Thus, there is an urgent need to understand the various health measures that dialogue with environmental, social and political actions that need to be built, in the various dimensions, in order to fight socio-environmental inequalities.

Keywords: COVID- 19; Agglomeration; Basic Sanitation; Environmental Pollution.

\title{
DETERMINACIONES SOCIALES DE LA SALUD Y LOS DESAFÍOS EN PROPAGAR Y COMBATIR COVID-19
}

\begin{abstract}
Resumen
A fines de 2019, se identificó una enfermedad infecciosa con una alta tasa de transmisión de persona a persona en Wuhan, China, que se llamó Covid-19. En poco tiempo, esta enfermedad afectó a varias regiones del mundo y se convirtió en una pandemia, con enormes impactos en la vida de las personas y el medio ambiente. Este artículo tiene como objetivo investigar las relaciones existentes entre la salud y el medio ambiente, en el momento de confrontar a Covid19 en Brasil, centrándose en los problemas socioambientales del saneamiento y la aglomeración y sus consecuencias / límites para la prevención / atención en Salud. Para el desarrollo de la investigación, se realizó una revisión sistemática entre mayo y junio de 2020. El artículo presenta aspectos sobre la revolución industrial y su relación con las formas de vida; La cuestión del saneamiento, la aglomeración como reflejo de las desigualdades geográficas y su impacto en la lucha contra Covid-19. Por lo tanto, existe una necesidad urgente de comprender las diversas medidas sanitarias que dialogan con las acciones ambientales, sociales y políticas que deben construirse, en las diferentes dimensiones, para combatir las desigualdades socioambientales.
\end{abstract}

Descritores: COVID- 19; Aglomeración; Saneamiento basico; Contaminación Ambiental. 